\title{
Electronic Health Record Use in Swiss Nursing Homes and Its Association With Implicit Rationing of Nursing Care Documentation: Multicenter Cross-sectional Survey Study
}

Dietmar Ausserhofer ${ }^{1,2}, \mathrm{PhD}$; Lauriane Favez ${ }^{2}$, MA; Michael Simon ${ }^{2,3}, \mathrm{PhD}$; Franziska Zúñiga ${ }^{2}, \mathrm{PhD}$

${ }^{1}$ College of Health Care-Professions Claudiana, Bolzano-Bozen, Italy

${ }^{2}$ Nursing Science, Department of Public Health, University of Basel, Basel, Switzerland

${ }^{3}$ Nursing Research Unit, Inselspital Bern University Hospital, Bern, Switzerland

Corresponding Author:

Franziska Zúñiga, PhD

Nursing Science

Department of Public Health

University of Basel

Bernoullistrasse 28

Basel, 4056

Switzerland

Phone: 41612070913

Email: franziska.zuniga@unibas.ch

\section{Abstract}

Background: Nursing homes (NHs) are increasingly implementing electronic health records (EHRs); however, little information is available on EHR use in NH settings. It remains unclear how care workers perceive its safety, quality, and efficiency, and whether EHR use might ease the burden of documentation, thereby reducing its implicit rationing.

Objective: This study aims to describe nurses' perceptions regarding the usefulness of the EHR system and whether sufficient numbers of computers are available in Swiss NHs, and to explore the system's association with implicit rationing of nursing care documentation.

Methods: This was a multicenter cross-sectional study using survey data from the Swiss Nursing Homes Human Resources Project 2018. It includes a convenience sample of 107 NHs, 302 care units, and 1975 care workers (ie, registered nurses and licensed practical nurses) from Switzerland's German- and French-speaking regions. Care workers completed questionnaires assessing the level of implicit rationing of nursing care documentation, their perceptions of the EHR system's usefulness and of how sufficient the number of available computers was, staffing and resource adequacy, leadership ability, and teamwork and safety climate. For analysis, we applied generalized linear mixed models, including individual-level nurse survey data and data on unit and facility characteristics.

Results: Overall, the care workers perceived the EHR systems as useful; ratings ranged from $69.42 \%$ (1362/1962; guarantees safe care and treatment) to $78.32 \%$ (1535/1960; allows quick access to relevant information on the residents). However, less than half $(914 / 1961,46.61 \%)$ of the care workers reported sufficient computers on their unit to allow timely documentation. Half of the care workers responded that they sometimes or often had to ration the documentation of care. After adjusting for work environment factors and safety and teamwork climate, both higher care worker ratings of the EHR system's usefulness ( $\beta=-.12$; $95 \%$ CI -0.17 to -0.06 ) and sufficient numbers of computers ( $\beta=-.09 ; 95 \%$ CI -0.12 to -0.06 ) were consistently associated with lower implicit rationing of nursing care documentation.

Conclusions: Both the usefulness of the EHR system and the number of computers available were important explanatory factors for care workers leaving care activities (eg, developing or updating nursing care plans) unfinished. NH managers should carefully select and implement their information technology infrastructure with greater involvement and attention to the needs of their care workers and residents. Further research is needed to develop and implement user-friendly information technology infrastructure in NHs and to evaluate their impact on care processes as well as resident and care worker outcomes.

(JMIR Med Inform 2021;9(3):e22974) doi: 10.2196/22974 


\section{KEYWORDS}

electronic health records; nursing homes; nursing care; health care rationing; rationing of nursing care; unfinished care; documentation; patient care planning; mobile phone

\section{Introduction}

\section{Background}

Health care organizations worldwide are increasingly using electronic health records (EHRs) to improve health care safety, quality, and efficiency. EHRs are defined as an electronic version of a person's medical history, including key administrative clinical data relevant to that person's care [1]. Although digital transformation in acute care is progressing quickly, the implementation of EHR in long-term care is following at a slower pace. In the United States, less than 50\% of nursing homes (NHs) have implemented EHRs, with nonprofit and government NHs, those with more than 100 beds, and those with higher staffing levels (ie, registered nurses [RNs] and certified nursing assistants) more likely to use EHRs [2-6]. Among the barriers identified for successful EHR implementation, $\mathrm{NH}$ settings were costs, the need for training, and the culture change required to embrace technology $[6,7]$.

Although little is known regarding the impact of EHR adoption on the provision of $\mathrm{NH}$ care, positive effects on the processes and outcomes of acute care provision have been reported. These include increased adherence to guideline-based care, enhanced surveillance and monitoring, improved clinical decision making, and decreased medication errors [8-13]. Despite concerns that EHR implementation might negatively impact safety and quality of care during the transition period, acute care studies found no differences between pre- and postimplementation on short-term inpatient mortality, adverse events, or readmissions [14]. Some benefits of EHR use (eg, increased access to resident information, cost avoidance, and increased documentation accuracy) are increasingly recognized by health care professionals, including physicians [15] and nurses [16].

Even if the overall quality of documentation is not improved in the electronic system, for example, in cases where paper-based documentation standards were already extremely high [17], one expected benefit of EHR is increased time efficiency. In fact, at least during the implementation phase, the opposite has been reported, with documentation time increasing from $16 \%$ to $28 \%$ for physicians and from 9\% to 23\% for nurses [18]. Although EHRs should support health care professionals by reducing their documentation burden, thus allowing them more time for dedicated patient care, this initial impact on their workloads might prove a major barrier to their implementation and long-term use [18].

Nurses spend around one-fifth of their working time on documentation activities, such as developing or updating nursing care plans [19]. Although these activities are considered crucial to the provision of high-quality professional NH care [20], these indirect care activities performed away from residents are often either rationed or missed. Nurses place higher priority on direct care activities, that is, those that require interactions with the residents or their families, such as assisting with drinking and food intake [21,22]. A previous study reported that NH care workers who reported less rationing of direct care, rehabilitation, monitoring, and social care activities tended to perceive the overall quality of $\mathrm{NH}$ care as higher, whereas they actually associated more rationing of documentation with better self-perceived quality of $\mathrm{NH}$ care [23].

Implicit rationing of nursing care or missed care-recently summarized also under the umbrella term unfinished nursing care [24] - has become a global phenomenon of concern affecting the safety and quality of hospital and $\mathrm{NH}$ care $[25,26]$. $\mathrm{NH}$ studies indicate that up to $75 \%$ of nurses leave at least one necessary care activity unfinished on every shift [22,27]. Implicit rationing of nursing care has been defined as "the withholding of or failure to carry out all needed nursing interventions in the face of inadequate time, staffing or skill mix" [28]. Although this mainly refers to direct care activities with residents, failure to document nursing care is equally dangerous, as it hinders continuity of care. As this study's conceptual model describes (Figure 1), alongside perceived shortfalls in the information technology (IT) infrastructure (ie, EHRs and computers), care workers' perceptions of facility and unit characteristics, work environment, teamwork and safety climate, and even individual care worker characteristics can all impact $\mathrm{NH}$ care provision processes, meaning they can also result in implicit rationing of nursing care, including documentation. Evidence supports this conceptual underpinning, as lower levels of nurse staffing [29] and teamwork and safety climate [21] were all associated with higher amounts of missed or rationed care. 
Figure 1. Conceptual framework: factors related to implicit rationing of nursing care documentation. EHR: electronic health records; FTE: full-time equivalent; RN: registered nurse.

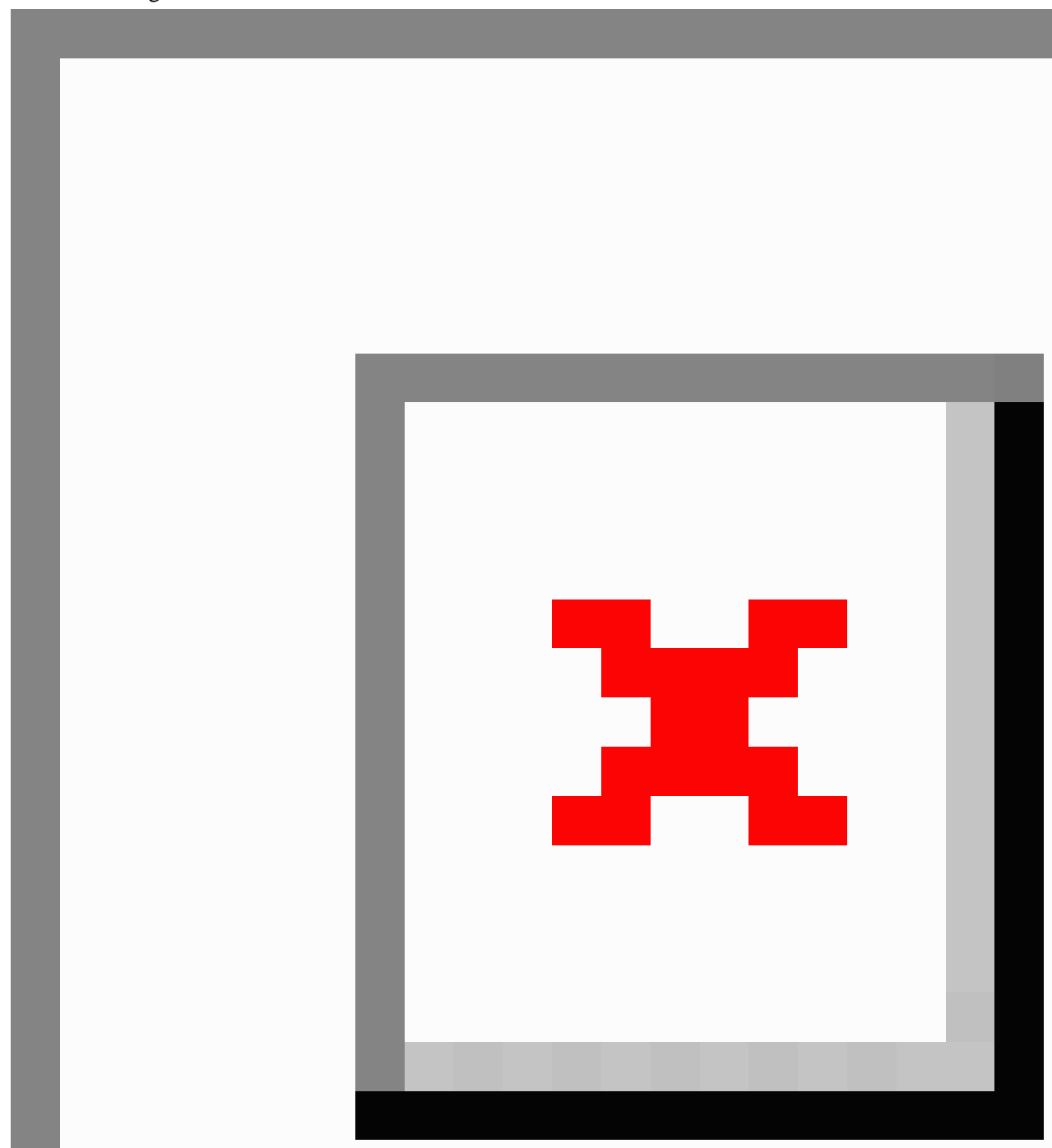

\section{Research Gap and Objectives}

To date, little information is available on EHR use in NHs, for example, how nurses, as the main users, perceive their workplace system's quality and efficiency. Moreover, it remains unclear what roles EHRs' uses and characteristics might have on $\mathrm{NH}$ care processes, for example, whether more efficient EHRs might reduce care workers' documentation burden, thereby reducing the perceived need to implicitly ration it and allowing better continuity of care. As increasing numbers of NHs have implemented EHRs in recent years with the objective of increasing efficiency, in this study, we aim (1) to explore Swiss NH care workers' perceptions regarding their EHR systems' usefulness and the sufficiency of the number of computers and (2) to explore the association between the IT infrastructure and implicit rationing of nursing care documentation.

\section{Methods}

\section{Study Design}

This study is based on data from the 2018 Swiss Nursing Home Human Resources Project (SHURP), a cross-sectional, multicenter study. 


\section{Sample and Setting}

A convenience sample of $107 \mathrm{NHs,} \mathrm{housing} 302$ care units, and 1975 care workers (ie, RNs and licensed practical nurses) in Switzerland's German- and French-speaking regions were included in this study. The mean response rate to the care worker survey was $66.0 \%$, ranging from $12.7 \%$ to $98.2 \%$ at the facility level. NHs who had participated in the first edition of the SHURP study (2013-2015) [30] were invited to participate in this new edition and were automatically included if they accepted. To increase the sample size, we sent waves of invitations to randomly selected NHs. In parallel, uninvited NHs that were willing to participate could contact the study team directly to be included. Finally, to further increase the inclusion rate, collaborations were set up with diverse $\mathrm{NH}$ associations. Additional NHs were included until March 2019. Inclusion criteria were that each $\mathrm{NH}$ was recognized by cantonal authorities and had a minimum of 20 beds.

\section{Data Collection}

The survey was administered, as appropriate, in two language versions, German and French, between September 2018 and October 2019. All directors of the participating NHs provided written consent to participate in the study. For care workers, sending back the voluntary care worker questionnaire was considered as informed consent.

\section{Ethical Aspects}

An ethics waiver was obtained from the responsible Swiss ethics committee (the Northwest and Central Switzerland ethics committee, BASEC Nr Req-2018-00420).

\section{Variables and Measures}

To measure the rationing of nursing care documentation, we used the 3-item subscale of the NH version of the Basel Extent of Rationing of Nursing Care instrument. Care workers were asked how often in the past 7 days they had been unable to study care plans at the beginning of their shift, set up or update residents' care plans, or document the care provided because of lack of time or high workload [31]. As lack of time or workload is a matter not only of resources (eg, staffing levels) but also of demand, EHR systems might increase the demand in terms of documentation.

The main explanatory variables were care workers' perceptions of the EHR system's usefulness (5 items) and sufficiency of the number of computers on the units (one item). These items were developed based on a literature review of EHR use in NHs $[32,33]$. The explanatory factor analyses of the internal structure of the 5 items on care workers' perceptions revealed a good fit, suggesting a one-dimensional solution (Tucker Lewis Index of factoring reliability $=0.976$; root mean square error of approximation index $=0.079$; 95\% CI 0.063-0.096; Cronbach $\alpha=.88$ ). Therefore, we calculated the scale's mean score. To facilitate further analyses, we kept the coding of the 5-point Likert scale of the single item assessing the sufficiency of computers on the units.

All potential confounding and control variables, including facility and unit characteristics, perceptions of work environment factors, teamwork and safety climate, and care worker characteristics, are described in Multimedia Appendix 1.

\section{Data Analyses}

Descriptive statistics (frequencies, percentages, means, and SDs) were calculated to describe the measured variables. To explore differences between care workers' professional backgrounds with regard to the EHR system's usefulness and whether a sufficient number of computers were available, we used chi-square tests. To explore the relationship between care workers' perceptions with regard to the EHR systems and whether sufficient computers were available and implicit rationing of nursing care documentation, 2-level generalized linear mixed models were used. On the basis of the intraclass correlation coefficient 1 (ICC1), which was $>0.05$, multilevel modeling was required [34]. Therefore, we computed ICC1 to assess the variability of the outcome variable (implicit rationing of nursing care documentation) between units and facilities. In this case, an ICC 1 of 0.155 at the unit level and 0.118 at the facility level indicated a need to account for the clustering of care worker data within units and facilities.

We report unadjusted (crude) associations and 2 adjusted models: (1) not including staffing and resources adequacy and (2) including staffing and resources adequacy. To compare the models' relative fits, we used Akaike information criterion; a lower value indicates a better fit. Data analyses were performed with R (version 3.4.2; R Foundation for Statistical Computing, 2017) using the rptR package for the calculation of ICC1 [35] and the lme4 package for generalized linear mixed models [36]. Depending on the variable, between $0.1 \%$ and $8.3 \%$ of the data for unit and facility characteristics were missing. In the nurse survey, data missing varied between $0.1 \%$ (ie, educational background) and $3 \%$ (ie, professional experience). A $P$ value of less than .05 was considered significant.

\section{Results}

\section{Sample Description}

This substudy used a sample of 1975 care workers. More than $90 \%$ were female; the majority were older than 41 years and had more than 5 years of professional experience. The majority worked part time, with employment levels between $51 \%$ and $90 \%$ and with regular changes in shifts. Of the 107 Swiss NHs included in the study, the majority were medium sized (between 50 and 100 beds) and private or privately subsidized. Table 1 summarizes the care worker, unit, and facility characteristics. 
Table 1. Facility, unit, and care worker characteristics.

\begin{tabular}{|c|c|c|c|}
\hline Facility and unit characteristics & $\begin{array}{l}\text { Total }\left(\mathrm{N}=107 \mathrm{NHs}^{\mathrm{a}}, 302\right. \\
\text { units, } 1975 \text { care workers })\end{array}$ & $\begin{array}{l}\text { German-speaking region ( } \mathrm{n}=88 \\
\mathrm{NHs}, 268 \text { units, } 1794 \text { care workers) }\end{array}$ & $\begin{array}{l}\text { French-speaking region ( } \mathrm{n}=19 \\
\text { NHs, } 34 \text { units, } 181 \text { care workers) }\end{array}$ \\
\hline \multicolumn{4}{|l|}{ NH size, n (\%) } \\
\hline Small ( $<50$ beds $)$ & $24(22.4)$ & $20(22.7)$ & $4(21.1)$ \\
\hline Medium (50-100 beds) & $55(51.4)$ & $42(47.8)$ & $13(68.4)$ \\
\hline Large (>100 beds) & $28(26.2)$ & $26(29.5)$ & $2(10.5)$ \\
\hline \multicolumn{4}{|l|}{ NH profit status, n (\%) } \\
\hline Public & $45(42.1)$ & $41(46.6)$ & $4(21.1)$ \\
\hline Privately subsidized or private & $62(57.9)$ & $47(53.4)$ & $15(78.9)$ \\
\hline \multicolumn{4}{|l|}{ NH unit characteristics } \\
\hline Clinical focus on dementia, n (\%) & $218(74.4)$ & $196(75.1)$ & $22(68.8)$ \\
\hline Bed capacity, median (IQR) & $24(12)$ & $24(12)$ & $29(19)$ \\
\hline $\begin{array}{l}\text { Full-time equivalent per } 100 \text { beds, medi- } \\
\text { an (IQR) }\end{array}$ & $48.5(23.2)$ & $48.0(23.4)$ & $51.6(16.8)$ \\
\hline $\begin{array}{l}\text { Skill mix level (\% registered nurse), } \\
\text { median (IQR) }\end{array}$ & $26.5(16.7)$ & $27.8(17.0)$ & $20.3(9.2)$ \\
\hline \multicolumn{4}{|l|}{ Care worker characteristics } \\
\hline \multicolumn{4}{|l|}{ Age (years), n (\%) } \\
\hline$<21$ & $127(6.46)$ & $120(6.73)$ & $7(3.87)$ \\
\hline $21-30$ & $408(20.76)$ & $361(20.24)$ & $47(25.97)$ \\
\hline $31-40$ & $336(17.10)$ & $295(16.54)$ & $41(22.65)$ \\
\hline $41-50$ & $396(20.15)$ & $360(20.18)$ & $36(19.89)$ \\
\hline $51-60$ & $556(28.30)$ & $519(29.09)$ & $37(20.44)$ \\
\hline$>60$ & $142(7.23)$ & $129(7.23)$ & $13(7.18)$ \\
\hline Gender: female, n (\%) & $1783(91.25)$ & $1613(90.92)$ & $170(94.44)$ \\
\hline \multicolumn{4}{|l|}{ Educational background, n (\%) } \\
\hline Registered nurse & $944(47.80)$ & $861(47.99)$ & $83(45.86)$ \\
\hline Licensed practical nurse & $1031(52.20)$ & $933(52.01)$ & $98(54.14)$ \\
\hline \multicolumn{4}{|l|}{ Tenure in current nursing home, $n(\%)$} \\
\hline Up to 5 years & $921(48.02)$ & $836(47.96)$ & $85(48.57)$ \\
\hline $5-10$ years & $387(20.18)$ & $348(19.97)$ & 39 (22.29) \\
\hline$\geq 10$ years & $610(31.80)$ & $559(32.07)$ & $51(29.14)$ \\
\hline \multicolumn{4}{|l|}{ Employment level, n (\%) } \\
\hline$<51 \%$ & $319(16.32)$ & $303(17.07)$ & $16(8.89)$ \\
\hline $51 \%-90 \%$ & $1105(56.52)$ & $982(55.32)$ & $123(68.33)$ \\
\hline $91 \%-100 \%$ & $531(27.16)$ & $490(27.61)$ & $41(22.78)$ \\
\hline \multicolumn{4}{|l|}{ Main shift, n (\%) } \\
\hline Regular change of shifts & $1003(50.99)$ & $921(51.57)$ & $82(45.30)$ \\
\hline Day evening shift & $783(39.81)$ & $702(39.31)$ & $81(44.75)$ \\
\hline Night shift & $181(9.20)$ & $163(9.12)$ & $18(9.95)$ \\
\hline
\end{tabular}

${ }^{\mathrm{a}} \mathrm{NH}$ : nursing home. 


\section{Variable Result Description}

\section{Care Workers' Perceptions of the EHR System's Usefulness and the Sufficiency of the Number of Computers on Their Unit}

Overall, the care workers perceived their facilities' EHR systems as useful (Table 2). The percentage agreeing or strongly agreeing with the respective statements ranged from $69.42 \%$ (guarantees safe care and treatment) to $78.32 \%$ (allows quick access to relevant information on the residents). However, less than half $(46.61 \%)$ of the care workers reported sufficient computers on their units to allow timely documentation.

As summarized in Table 2, we observed differences between RNs' and licensed practical nurses' perceptions as well as between language regions. For instance, compared with RNs, licensed practical nurses more often agreed that the EHR system gives a good daily overview of all residents on the care unit.

Table 2. Care workers' perception of the electronic health record system's usefulness and of whether the number of computers was sufficient (N=1975).

\begin{tabular}{|c|c|c|c|c|}
\hline \multirow{2}{*}{$\begin{array}{l}6 \text { items on care workers' perceptions of the electronic health } \\
\text { record system's usefulness and sufficiency of the number of } \\
\text { computers on the units }\end{array}$} & \multirow[t]{2}{*}{ Total $(\mathrm{N}=1975), \mathrm{n}\left(\%^{\mathrm{a}}\right)$} & \multicolumn{2}{|c|}{ Educational background, n $\left(\%^{\mathrm{a}}\right)$} & \multirow[t]{2}{*}{$P$ value $^{\mathrm{b}}$} \\
\hline & & $\begin{array}{l}\text { Registered nurses } \\
(\mathrm{n}=966)\end{array}$ & $\begin{array}{l}\text { Licensed practical nurses } \\
(\mathrm{n}=1058)\end{array}$ & \\
\hline $\begin{array}{l}\text { The electronic health record system allows timely communi- } \\
\text { cation between the nursing and therapy teams }\end{array}$ & 1367 (69.96) & 667 (71.11) & $700(68.90)$ & .29 \\
\hline $\begin{array}{l}\text { The electronic health record system provides a good overview } \\
\text { on the main focus of care and treatment for the individual } \\
\text { residents }\end{array}$ & 1507 (76.89) & $710(75.53)$ & 797 (78.14) & .17 \\
\hline $\begin{array}{l}\text { The electronic health record system gives a good daily } \\
\text { overview on all residents on the care unit }\end{array}$ & $1429(72.98)$ & 664 (70.78) & $765(75.00)$ & .04 \\
\hline $\begin{array}{l}\text { The electronic health record system guarantees safe care and } \\
\text { treatment }\end{array}$ & $1362(69.42)$ & $645(68.54)$ & 717 (70.23) & .42 \\
\hline $\begin{array}{l}\text { The electronic health record system allows quick access to } \\
\text { relevant information on the residents }\end{array}$ & $1535(78.32)$ & $720(76.51)$ & 815 (79.98) & .06 \\
\hline $\begin{array}{l}\text { On our unit there are sufficient computers to allow timely } \\
\text { documentation }\end{array}$ & 914 (46.61) & $451(47.98)$ & $463(45.35)$ & .24 \\
\hline
\end{tabular}

${ }^{\mathrm{a}}$ Percentage agreement (agree and strongly agree).

${ }^{\mathrm{b}}$ Chi-square test, $P<.05$ highlighted in italic.

\section{Implicit Rationing of Nursing Care Documentation, Work Environment, and Teamwork and Safety Climate}

Approximately half of the care workers responded that they sometimes or often had to ration care activities related to documentation (range: $46.02 \%$ [studying care plans] to $50.06 \%$ [set up or update residents' care plans]; Table 3). The mean rating for implicit rationing of nursing care documentation was 2.38 (SD 0.90; rarely to sometimes). As Table 4 shows, care workers rated adequate staffing and resources at the neutral midpoint (mean 2.67, SD 0.67) and strongly felt that they were supported by leadership (mean 3.18, SD 0.62). The mean teamwork and safety climate was rated as favorable (mean 3.89, SD 0.81). Furthermore, ICCs of the rationing of documentation items and whether sufficient numbers of computers were available ranged between 0.077 and 0.221 , indicating substantial variation between units and between facilities (Table 4).

Table 3. Frequencies of implicit rationing of nursing care documentation $(\mathrm{N}=1975)$.

\begin{tabular}{llllll}
\hline $\begin{array}{l}\text { Care activities rationed by care workers in the } \\
\text { last } 7 \text { days }\end{array}$ & $\begin{array}{l}\text { Activity not necessary, } \\
\mathrm{n}(\%)\end{array}$ & Never, n (\%) & Seldom, n (\%) & Sometimes, n (\%) & Often, n (\%) \\
\hline $\begin{array}{l}\text { Studying care plans at the beginning of the } \\
\text { shift }\end{array}$ & $13(0.67)$ & $478(24.72)$ & $553(28.59)$ & $480(24.82)$ & $410(21.2)$ \\
$\begin{array}{l}\text { Set up or update residents' care plans } \\
\text { Documentation of care }\end{array}$ & $110(6.83)$ & $270(16.77)$ & $424(26.34)$ & $481(29.88)$ & $325(20.19)$ \\
\hline
\end{tabular}


Table 4. Characteristics of variables under study $(\mathrm{N}=1975)$.

\begin{tabular}{|c|c|c|c|}
\hline Variables & Mean (SD) & Facility level, $\mathrm{ICC}^{\mathrm{a}}(95 \% \mathrm{CI})$ & Unit level, ICC1 (95\% CI) \\
\hline Rationing of nursing care documentation & $2.38(0.9)$ & $0.118(0.076-0.165)$ & $0.155(0.111-0.202)$ \\
\hline $\begin{array}{l}\text { Care workers' perception of the electronic health record system's } \\
\text { usefulness }\end{array}$ & $3.86(0.77)$ & $0.077(0.043-0.112)$ & $0.097(0.064-0.135)$ \\
\hline Care workers' perception of sufficient number of computers & $3.13(1.33)$ & $0.116(0.072-0.161)$ & $0.221(0.176-0.269)$ \\
\hline \multicolumn{4}{|l|}{ Work environment } \\
\hline Leadership & $3.18(0.62)$ & $0.156(0.104-0.205)$ & $0.278(0.228-0.326)$ \\
\hline Staffing and resources adequacy & $2.67(0.67)$ & $0.214(0.151-0.271)$ & $0.254(0.207-0.302)$ \\
\hline Teamwork and safety climate & $3.89(0.81)$ & $0.111(0.068-0.156)$ & $0.196(0.152-0.244)$ \\
\hline
\end{tabular}

${ }^{\mathrm{a}} \mathrm{ICC} 1$ : intraclass correlation coefficient 1 .

\section{Factors Associated With Implicit Rationing of Nursing Care Documentation}

In the crude models (Table 5), as well as models 1 and 2 (Table 6), care workers' perceptions of both the EHR system's usefulness and whether a sufficient number of computers were available were significantly associated with implicit rationing of nursing care documentation. More positive care workers' perceptions of the EHR system's usefulness ( $\beta=-.12 ; 95 \%$ CI -0.17 to -0.06$)$ and of the sufficiency of the number of computers ( $\beta=-.09 ; 95 \% \mathrm{CI}-0.12$ to -0.06$)$ were associated with lower implicit rationing of nursing care documentation (model 2). 
Table 5. Implicit rationing of nursing care documentation regressed on care workers' perceptions of their electronic health record systems and the sufficiency of the number of computers, along with facility, unit and care worker characteristics and staffing variables, work environment, and teamwork and safety climate.

\begin{tabular}{|c|c|c|}
\hline \multirow[t]{2}{*}{ Variables } & \multicolumn{2}{|l|}{ Crude models $^{\mathrm{a}}$} \\
\hline & $\beta(95 \% \mathrm{CI})$ & SE \\
\hline \multicolumn{3}{|l|}{ Explanatory variables } \\
\hline $\begin{array}{l}\text { Care workers' perception of the electronic health record system's } \\
\text { usefulness }\end{array}$ & $-.31^{\mathrm{b}}(-0.36$ to -0.26$)$ & 0.03 \\
\hline $\begin{array}{l}\text { Care workers' perception of whether sufficient numbers of computers } \\
\text { were available on their units }\end{array}$ & $-.19^{\mathrm{b}}(-0.21$ to -0.16$)$ & 0.02 \\
\hline \multicolumn{3}{|l|}{ Control variables } \\
\hline \multicolumn{3}{|l|}{ Facility characteristics } \\
\hline Language region & $0.18(-0.03$ to 0.40$)$ & 0.11 \\
\hline Nursing home size & $-.03(-0.14$ to 0.08$)$ & 0.05 \\
\hline Profit status & $-.04(-0.19$ to 0.12$)$ & 0.08 \\
\hline Electronic health record system & 0.01 (-0.01-to 0.04$)$ & 0.01 \\
\hline \multicolumn{3}{|l|}{ Unit characteristics } \\
\hline Staffing levels & $0(-0.01$ to 0.00$)$ & 0 \\
\hline Skill mix levels & $0(-0.01$ to 0.00$)$ & 0 \\
\hline \multicolumn{3}{|l|}{ Work environment } \\
\hline Leadership & $-.37^{\mathrm{b}}(-0.44$ to -0.31$)$ & 0.03 \\
\hline Staffing and resources adequacy & $-.63^{\mathrm{b}}(-0.69$ to -0.58$)$ & 0.03 \\
\hline Safety and teamwork climate & $-.39^{\mathrm{b}}(-0.46$ to -0.34$)$ & 0.03 \\
\hline \multicolumn{3}{|l|}{ Care workers' characteristics } \\
\hline Gender & $-.07(-0.21$ to 0.06$)$ & 0.07 \\
\hline Age & $0.01(-0.02$ to 0.03$)$ & 0.01 \\
\hline Educational background & $-.08^{\mathrm{b}}(-0.16$ to -0.01$)$ & 0.04 \\
\hline Professional experience & $0.04(-0.01$ to 0.08$)$ & 0.02 \\
\hline Employment level & $-.04(-0.09$ to 0.03$)$ & 0.03 \\
\hline Fixed effects (intercept) & $2.39^{\mathrm{b}}(2.32$ to 2.47$)$ & 0.03 \\
\hline
\end{tabular}

${ }^{\mathrm{a}}$ Random effect: Facility-level variance $(\mathrm{SD})=0.07(0.27)$, Unit-level variance $(\mathrm{SD})=0.06(0.25)$.

${ }^{\mathrm{b}} P$ value less than .05 .

Higher ratings of leadership and safety teamwork climate were significantly associated with lower levels of implicit rationing of nursing care documentation only in model 1 (not accounting for staffing and resource adequacy). In model 2, care worker-perceived staffing and resources adequacy was the strongest explanatory factor, that is, higher ratings for staffing and resources adequacy were associated with lower levels of implicit rationing of nursing care documentation $(\beta=-.52 ; 95 \%$ CI -0.58 to -0.45$)$. Moreover, care workers' educational backgrounds were significantly associated with implicit rationing of nursing care documentation in both models (Table 6 ), with licensed practical nurses in both cases reporting lower levels of rationing of nursing care documentation than RNs ( $\beta=-.09 ; 95 \% \mathrm{CI}-0.15$ to -0.02 ). 
Table 6. Implicit rationing of nursing care documentation regressed on care workers' perceptions of their electronic health record systems and the sufficiency of the number of computers, along with facility, unit and care worker characteristics and staffing variables, work environment, and teamwork and safety climate.

\begin{tabular}{|c|c|c|c|c|}
\hline \multirow[t]{2}{*}{ Variables } & \multicolumn{2}{|c|}{$\begin{array}{l}\text { Multiple model } 1^{\mathrm{a}} \text { (without staffing and re- } \\
\text { sources adequacy) }\end{array}$} & \multicolumn{2}{|c|}{$\begin{array}{l}\text { Multiple model } 2^{\mathrm{a}} \text { (with staffing and re- } \\
\text { sources adequacy) }\end{array}$} \\
\hline & $\beta(95 \% \mathrm{CI})$ & SE & $\beta(95 \% \mathrm{CI})$ & SE \\
\hline \multicolumn{5}{|l|}{ Explanatory variables } \\
\hline $\begin{array}{l}\text { Care workers' perception of the EHR }{ }^{b} \text { system's useful- } \\
\text { ness }\end{array}$ & $-.14^{\mathrm{c}}(-0.20$ to -0.09$)$ & 0.03 & $-.12^{\mathrm{c}}(-0.17$ to -0.06$)$ & 0.03 \\
\hline $\begin{array}{l}\text { Care workers' perception of whether sufficient num- } \\
\text { bers of computers were available on their units }\end{array}$ & $-.12^{\mathrm{c}}(-0.15$ to -0.09$)$ & 0.02 & $-.09^{\mathrm{c}}(-0.12$ to -0.06$)$ & 0.01 \\
\hline \multicolumn{5}{|l|}{ Control variables } \\
\hline \multicolumn{5}{|l|}{ Facility characteristics } \\
\hline Language region & $-^{d}$ & - & - & - \\
\hline Nursing home size & - & - & - & - \\
\hline Profit status & - & - & - & - \\
\hline EHR system & - & - & - & - \\
\hline \multicolumn{5}{|l|}{ Unit characteristics } \\
\hline Staffing levels & - & - & - & - \\
\hline Skill mix levels & - & - & - & - \\
\hline \multicolumn{5}{|l|}{ Work environment } \\
\hline Leadership & $-.12^{\mathrm{c}}(-0.21$ to -0.04$)$ & 0.04 & $0.08(-0.04$ to 0.12$)$ & 0.04 \\
\hline Staffing and resources adequacy & - & - & $-.52^{\mathrm{c}}(-0.58$ to -0.45$)$ & 0.03 \\
\hline Safety and teamwork climate & $-.20^{\mathrm{c}}(-0.27$ to -0.12$)$ & 0.04 & $-.08^{\mathrm{c}}(-0.15$ to -0.01$)$ & 0.04 \\
\hline \multicolumn{5}{|l|}{ Care workers' characteristics } \\
\hline Gender & - & - & - & - \\
\hline Age & - & - & - & - \\
\hline Educational background & $-.08^{\mathrm{c}}(-0.16$ to -0.02$)$ & 0.04 & $-.09^{\mathrm{c}}(-0.15$ to -0.02$)$ & 0.04 \\
\hline Professional experience & - & - & - & - \\
\hline Employment level & - & - & - & - \\
\hline Fixed effects (intercept) & $4.67^{\mathrm{c}}$ (4.39 to 4.94$)$ & 0.14 & $4.80^{\mathrm{c}}$ (4.53 to 5.05$)$ & 0.13 \\
\hline
\end{tabular}

${ }^{a}$ Random effects: Multiple model 1: Facility-level variance $(\mathrm{SD})=0.05(0.22)$, Unit-level variance $(\mathrm{SD})=0.04(0.21)$, Akaike information criterion=4598.8; Multiple model 2: Facility-level variance $(S D)=0.03(0.17)$, Unit-level variance $(S D)=0.01(0.12)$, Akaike information criterion $=4405.8$.

${ }^{\mathrm{b}}$ EHR: electronic health record.

${ }^{\mathrm{c}} P$ value $<.05$.

${ }^{\mathrm{d}}$ Variable not included in the model.

\section{Discussion}

\section{Principal Findings}

In this study, we aimed to explore Swiss NH care workers' perceptions of their EHR systems' usefulness, whether their units had sufficient numbers of computers, and the association with rationing of nursing care documentation. Overall, the majority of care workers perceived the EHR systems as useful; however, fewer than half of the care workers reported having sufficient computers on their unit to allow timely documentation, and more than half of the care workers reported sometimes or often having to ration care activities related to documentation. Higher implicit rationing of nursing care documentation was reported by those who rated their EHR system's usefulness as low and the number of computers as insufficient.

Most care workers in our study sample perceived that the EHR was useful, for example, that it provided a good overview of the main focus of care and treatment and allowed quick access to relevant information on residents. Earlier studies have found that various advantages of EHR compared with traditional paper records were reported in long-term care settings. These included the structured collection of and accessibility to information 
about residents' family histories, contact information, medications, information regarding current and previous care, medical treatments and procedures, and other relevant health-related information [37]. Likewise, Swiss care workers appreciated the various benefits of their EHR systems. Although EHRs are supposed to improve the safety and quality of care by offering tools (eg, alerts and reminders) to help avoid adverse events such as those related to medication errors [8-12], nearly one-third of our sample did not consider the EHR useful for guaranteeing safe care and treatment. We cannot explain this perception, but it could be based on the structure, accessibility, monitoring tools, usability, or other aspects of EHRs as well as on the handling and common understanding of a team about how to deal with the system.

It is clear, however, that EHR use does not automatically improve documentation, that is, its adoption does not necessarily mean that its users will provide timelier, more complete records; better continuity of care; or safer care or treatments [38]. Although safety concerns linked to EHR implementation, especially during the initial adjustment to digital documentation, have been reported elsewhere [39], once care workers are familiar with their particular systems [40], EHRs ultimately have a strong potential to improve the quality and safety of workflows. As with other systems that have delivered widespread improvements, the expected benefits of EHR can only be achieved in real-world settings through continuous feedback and improvement [41]. Improving our understanding of how EHRs contribute to safe care and how their use in NHs may actually lead to safety issues will require further qualitative research.

One less complicated matter is that half of our respondents reported not having sufficient computers on their units for the timely completion of their documentation. Care workers, especially RNs, spend a considerable amount of their working time on documentation activities, such as developing or updating nursing care plans [19]. A lack of computers on the unit (often there is only one) might impede timely care planning and documentation and increase the documentation burden. Therefore, NHs need to allow care workers timely access to EHRs and avoid waiting times. For example, to eliminate waiting time for computers, it may be practical to perform activities such as developing or updating nursing care plans or documenting nursing care in real time at the patient's bedside via mobile devices (eg, tablets or smartphones). Currently, however, no evidence is available on the effects or acceptability of such devices by $\mathrm{NH}$ care workers to either improve documentation or to reduce rationing of nursing care documentation. Further research on this topic is required.

More than half of our care worker sample responded that they sometimes or often had to ration documentation-related care activities. Tasks such as developing or updating nursing care plans or documenting nursing care are important parts of daily patient care; however, they are often perceived as keeping care workers away from the residents. However, it might be some time before EHR technology can meet care workers' initial expectations that EHR use will reduce their documentation time, allowing them more time for direct care activities.
In fact, initial adjustment to EHR may even increase documentation time [18]. Although health care is a complex, adaptive system, the software is not. It is complex, but adaptation tends to result from incremental and iterative improvements. Initially, this limitation might be the heart of the problem for $\mathrm{NH}$ care workers: rather than following and lightening their daily workload, they might find that EHR largely determines and adds to it [42].

After adjusting for important factors, our analysis showed that rationing of nursing documentation is consistently related to care workers' perceptions of both their EHR systems' usefulness and the sufficiency of the number of computers available to them. This finding provides new insights on why these indirect care activities often remain unfinished [21,22]. Former evidence has shown that work environment factors such as leadership and staffing and resources adequacy as well as the safety and teamwork climate explain certain levels of $\mathrm{NH}$ care rationing $[21,43]$. In addition, we now see that both EHRs' general lack of user-friendliness and the general unit-level shortage of documentation workstations are important factors explaining care workers' tendency to leave indirect care activities, such as developing or updating nursing care plans or documenting nursing care, unfinished.

As this leaves information gaps in the EHR, documentation rationing is likely accompanied by work-arounds, such as exchanging vital daily information on paper and via oral handovers to provide continuity of care. In other situations, information may simply be lost. Apart from presenting obvious legal problems if documentation is lacking or untraceable, both options increase the risk of adverse events and reduce the quality of care.

In our study sample alone, we found 12 separate EHR systems, which might differ regarding key EHR domains (eg, data transfer, structured clinical documentation, medication use processes, and communication) [44]. EHRs target a large and growing global market; according to a recently published report from Fortune Business Insights, a compound annual growth rate of $5.4 \%$ is expected until 2026 [45]. As buyers in that market, NH management could more forcefully demand IT solutions that support care workers' documentation needs while increasing safety and quality of care. EHR providers can reasonably be called upon to develop and design their software with input from all stakeholders-especially their users - in real-world settings. Therefore, care workers should be actively involved in testing and implementing the proposed IT infrastructure to ensure that, from the moment of implementation, it actually reduces their documentation burden [40].

\section{Limitations}

First, the cross-sectional design of the study did not allow inference of causal relationships. Second, as both the outcome variable (rationing of nursing care documentation) and the main explanatory variables (both involving perceptions of IT infrastructure) were assessed via a care worker survey, this measure might have introduced common method bias. Third, we unfortunately did not measure when each $\mathrm{NH}$ implemented its EHR, what basic and/or continuous training care workers 
receive to use the EHR, or to what extent staff managers encourage or monitor the care workers in using the EHR information, which could have helped explain the association between care workers' perceptions regarding IT infrastructure and implicit rationing of nursing care documentation.

\section{Conclusions}

Although the surveyed RNs' and licensed practical nurses' overall perception of EHR systems' usefulness in Swiss NHs was high, only half of the care workers reported having sufficient numbers of computers on their units. After adjusting for other main explanatory variables, our analyses indicated that more positive perceptions of both EHR systems' usefulness and the sufficiency of the number of computers on their units were associated with less rationing of nursing care documentation. Thus, both the EHR system and the number of available computers influence care workers' decision to leave indirect care activities, such as developing or updating nursing care plans or documenting nursing care, unfinished. Bearing this in mind, $\mathrm{NH}$ managers should carefully select and implement their IT infrastructure with full engagement and according to the needs of the end users, that is, their care workers, as well as their residents. Although EHRs are increasingly implemented in NHs, there is still little evidence on how their use influences the safety and quality of $\mathrm{NH}$ care, including as it relates to efficiency. Future challenges to the research concerning EHR use in NHs are (1) to identify user-friendly designs and successful implementations of related IT infrastructure in NHs (eg, EHR access via mobile devices) and (2) to evaluate the impact of EHR implementation in $\mathrm{NH}$ settings not only on both direct and indirect care processes but also on resident and care worker outcomes.

\section{Authors' Contributions}

FZ and LF developed the idea for this study. MS, LF, and FZ contributed to the concept, design, and data collection. DA, MS, and FZ contributed to data analysis and interpretation. DA contributed to drafting of the manuscript. All authors contributed to the critical revision of the manuscript and approved the final version.

\section{Conflicts of Interest}

None declared.

\section{Multimedia Appendix 1}

Study variables.

[DOC File, 55 KB-Multimedia Appendix 1]

\section{References}

1. Electronic Health Records. CMS. 2012. URL: https://www.cms.gov/Medicare/E-Health/EHealthRecords [accessed 2021-02-16]

2. Bjarnadottir RI, Herzig CT, Travers JL, Castle NG, Stone PW. Implementation of electronic health records in US nursing homes. Comput Inform Nurs 2017 Aug;35(8):417-424. [doi: 10.1097/CIN.0000000000000344] [Medline: 28800581]

3. Abramson EL, McGinnis S, Moore J, Kaushal R. A statewide assessment of electronic health record adoption and health information exchange among nursing homes. Health Serv Res 2014 Feb;49(1 Pt 2):361-372 [FREE Full text] [doi: 10.1111/1475-6773.12137] [Medline: 24359612]

4. Park-Lee E, Rome V, Caffrey C. Characteristics of residential care communities that use electronic health records. Am J Manag Care 2015 Dec 1;21(12):e669-e676 [FREE Full text] [Medline: 26760430]

5. Holup AA, Dobbs D, Temple A, Hyer K. Going digital: adoption of electronic health records in assisted living facilities. J Appl Gerontol 2014 Jun;33(4):494-504. [doi: 10.1177/0733464812454009] [Medline: 24781968]

6. Holup AA, Dobbs D, Meng H, Hyer K. Facility characteristics associated with the use of electronic health records in residential care facilities. J Am Med Inform Assoc 2013;20(4):787-791 [FREE Full text] [doi: 10.1136/amiajnl-2012-001564] [Medline: 23645538]

7. Cherry B, Carter M, Owen D, Lockhart C. Factors affecting electronic health record adoption in long-term care facilities. J Healthc Qual 2008;30(2):37-47. [Medline: 18411891]

8. McCarthy B, Fitzgerald S, O'Shea M, Condon C, Hartnett-Collins G, Clancy M, et al. Electronic nursing documentation interventions to promote or improve patient safety and quality care: A systematic review. J Nurs Manag 2019 Apr;27(3):491-501. [doi: 10.1111/jonm.12727] [Medline: 30387215]

9. Campanella P, Lovato E, Marone C, Fallacara L, Mancuso A, Ricciardi W, et al. The impact of electronic health records on healthcare quality: a systematic review and meta-analysis. Eur J Public Health 2016 Feb;26(1):60-64. [doi: 10.1093/eurpub/ckv122] [Medline: 26136462]

10. Chaudhry B, Wang J, Wu S, Maglione M, Mojica W, Roth E, et al. Systematic review: impact of health information technology on quality, efficiency, and costs of medical care. Ann Intern Med 2006 May 16;144(10):742-752. [Medline: 16702590] 
11. Poissant L, Pereira J, Tamblyn R, Kawasumi Y. The impact of electronic health records on time efficiency of physicians and nurses: a systematic review. J Am Med Inform Assoc 2005 Oct;12(5):505-516 [FREE Full text] [doi: 10.1197/jamia.M1700] [Medline: 15905487$]$

12. Garg AX, Adhikari NKJ, McDonald H, Rosas-Arellano MP, Devereaux PJ, Beyene J, et al. Effects of computerized clinical decision support systems on practitioner performance and patient outcomes: a systematic review. J Am Med Assoc 2005 Mar 9;293(10):1223-1238. [doi: 10.1001/jama.293.10.1223] [Medline: 15755945]

13. Kruse CS, Mileski M, Vijaykumar AG, Viswanathan SV, Suskandla U, Chidambaram Y. Impact of electronic health records on long-term care facilities: systematic review. JMIR Med Inform 2017 Sep 29;5(3):e35 [FREE Full text] [doi: 10.2196/medinform.7958] [Medline: 28963091]

14. Barnett ML, Mehrotra A, Jena AB. Adverse inpatient outcomes during the transition to a new electronic health record system: observational study. Br Med J 2016 Jul 28;354:i3835 [FREE Full text] [Medline: 27471242]

15. King J, Patel V, Jamoom EW, Furukawa MF. Clinical benefits of electronic health record use: national findings. Health Serv Res 2014 Feb;49(1 Pt 2):392-404 [FREE Full text] [doi: 10.1111/1475-6773.12135] [Medline: 24359580]

16. Cherry BJ, Ford EW, Peterson LT. Experiences with electronic health records: early adopters in long-term care facilities. Health Care Manage Rev 2011;36(3):265-274. [doi: 10.1097/HMR.0b013e31820e110f] [Medline: 21646885]

17. Wang N, Yu P, Hailey D. The quality of paper-based versus electronic nursing care plan in Australian aged care homes: A documentation audit study. Int J Med Inform 2015 Aug;84(8):561-569. [doi: 10.1016/j.ijmedinf.2015.04.004] [Medline: 26004340]

18. Baumann LA, Baker J, Elshaug AG. The impact of electronic health record systems on clinical documentation times: a systematic review. Health Policy 2018 Dec;122(8):827-836. [doi: 10.1016/j.healthpol.2018.05.014] [Medline: 29895467]

19. Yee T, Needleman J, Pearson M, Parkerton P, Parkerton M, Wolstein J. The influence of integrated electronic medical records and computerized nursing notes on nurses' time spent in documentation. Comput Inform Nurs 2012 Jun;30(6):287-292. [doi: 10.1097/NXN.0b013e31824af835] [Medline: 22411414]

20. Johnson L, Edward K, Giandinoto J. A systematic literature review of accuracy in nursing care plans and using standardised nursing language. Collegian 2018 Jun;25(3):355-361. [doi: 10.1016/j.colegn.2017.09.006]

21. Zúñiga F, Ausserhofer D, Hamers JPH, Engberg S, Simon M, Schwendimann R. The relationship of staffing and work environment with implicit rationing of nursing care in Swiss nursing homes--A cross-sectional study. Int J Nurs Stud 2015 Sep;52(9):1463-1474. [doi: 10.1016/j.ijnurstu.2015.05.005] [Medline: 26032730]

22. Nelson ST, Flynn L. Relationship between missed care and urinary tract infections in nursing homes. Geriatr Nurs 2015;36(2):126-130. [doi: 10.1016/j.gerinurse.2014.12.009] [Medline: 25563066]

23. Zúñiga F, Ausserhofer D, Hamers JPH, Engberg S, Simon M, Schwendimann R. Are staffing, work environment, work stressors, and rationing of care related to care workers' perception of quality of care? A cross-sectional study. J Am Med Dir Assoc 2015 Oct 1;16(10):860-866. [doi: 10.1016/j.jamda.2015.04.012] [Medline: 26027721]

24. Jones TL, Hamilton P, Murry N. Unfinished nursing care, missed care, and implicitly rationed care: State of the science review. Int J Nurs Stud 2015 Jun;52(6):1121-1137. [doi: 10.1016/j.ijnurstu.2015.02.012] [Medline: 25794946]

25. Recio-Saucedo A, Dall'Ora C, Maruotti A, Ball J, Briggs J, Meredith P, et al. What impact does nursing care left undone have on patient outcomes? Review of the literature. J Clin Nurs 2018 Jun;27(11-12):2248-2259 [FREE Full text] [doi: 10.1111/jocn.14058] [Medline: 28859254]

26. Ausserhofer D, Zander B, Busse R, Schubert M, De GS, Rafferty AM, RN4CAST consortium. Prevalence, patterns and predictors of nursing care left undone in European hospitals: results from the multicountry cross-sectional RN4CAST study. BMJ Qual Saf 2014 Feb;23(2):126-135. [doi: 10.1136/bmjqs-2013-002318] [Medline: 24214796]

27. Knopp-Sihota JA, Niehaus L, Squires JE, Norton PG, Estabrooks CA. Factors associated with rushed and missed resident care in western Canadian nursing homes: a cross-sectional survey of health care aides. J Clin Nurs 2015 Oct;24(19-20):2815-2825. [doi: 10.1111/jocn.12887] [Medline: 26177787]

28. Schubert M, Glass TR, Clarke SP, Schaffert-Witvliet B, De Geest S. Validation of the basel extent of rationing of nursing care instrument. Nurs Res 2007;56(6):416-424. [doi: 10.1097/01.NNR.0000299853.52429.62] [Medline: 18004188]

29. Griffiths P, Recio-Saucedo A, Dall'Ora C, Briggs J, Maruotti A, Meredith P, Missed Care Study Group. The association between nurse staffing and omissions in nursing care: a systematic review. J Adv Nurs 2018 Jul;74(7):1474-1487. [doi: 10.1111/jan.13564] [Medline: 29517813]

30. Schwendimann R, Zúñiga F, Ausserhofer D, Schubert M, Engberg S, de Geest S. Swiss Nursing Homes Human Resources Project (SHURP): protocol of an observational study. J Adv Nurs 2014 Apr;70(4):915-926. [doi: 10.1111/jan.12253] [Medline: 24102650]

31. Zúñiga F, Schubert M, Hamers JPH, Simon M, Schwendimann R, Engberg S, et al. Evidence on the validity and reliability of the German, French and Italian nursing home version of the Basel Extent of Rationing of Nursing Care instrument. J Adv Nurs 2016 Aug;72(8):1948-1963. [doi: 10.1111/jan.12975] [Medline: 27062508]

32. Xiao Y, Montgomery DC, Philpot LM, Barnes SA, Compton J, Kennerly D. Development of a tool to measure user experience following electronic health record implementation. J Nurs Admin 2014;44(7/8):423-428. [doi: 10.1097/nna.0000000000000093] 
33. Meehan R. Electronic health records in long-term care: staff perspectives. J Appl Gerontol 2017 Oct;36(10):1175-1196. [doi: 10.1177/0733464815608493] [Medline: 26464335]

34. LeBreton J, Senter JL. Answers to 20 questions about interrater reliability and interrater agreement. Organizational Research Methods 2008:815-852 [FREE Full text] [doi: 10.1177/1094428106296642]

35. Stoffel MA, Nakagawa S, Schielzeth H. rptR: repeatability estimation and variance decomposition by generalized linear mixed - effects models. Methods Ecol Evol 2017 May 30;8(11):1639-1644. [doi: 10.1111/2041-210x.12797]

36. Bates D, Mächler M, Bolker B, Walker S. Fitting linear mixed-effects models using. J Stat Soft 2015;67(1):-. [doi: 10.18637/jss.v067.i01]

37. Kruse CS, Mileski M, Alaytsev V, Carol E, Williams A. Adoption factors associated with electronic health record among long-term care facilities: a systematic review. BMJ Open 2015 Jan 28;5(1):e006615 [FREE Full text] [doi: 10.1136/bmjopen-2014-006615] [Medline: 25631311]

38. Wang N, Yu P, Hailey D. Description and comparison of documentation of nursing assessment between paper-based and electronic systems in Australian aged care homes. Int J Med Inform 2013 Sep;82(9):789-797. [doi: 10.1016/j.ijmedinf.2013.05.002] [Medline: 23786709]

39. Harrington L, Kennerly D, Johnson C. Safety issues related to the electronic medical record (EMR): synthesis of the literature from the last decade, 2000-2009. J Healthc Manag 2011;56(1):31-43; discussion 43. [Medline: 21323026]

40. Ko M, Wagner L, Spetz J. Nursing home implementation of health information technology: review of the literature finds inadequate investment in preparation, infrastructure, and training. Inquiry 2018;55:46958018778902. [doi: 10.1177/0046958018778902] [Medline: 29888677]

41. Singh H, Sittig DF. Measuring and improving patient safety through health information technology: the Health IT Safety Framework. BMJ Qual Saf 2015 Sep 14;25(4):226-232. [doi: 10.1136/bmjqs-2015-004486]

42. De Groot K, De Veer AJE, Paans W, Francke AL. Use of electronic health records and standardized terminologies: a nationwide survey of nursing staff experiences. Int J Nurs Stud 2020 Apr;104:103523. [doi: 10.1016/j.ijnurstu.2020.103523] [Medline: 32086028]

43. Zúñiga F, Ausserhofer D, Hamers JP, Engberg S, Simon M, Schwendimann R. Are staffing, work environment, work stressors, and rationing of care related to care workers' perception of quality of care? A cross-sectional study. $\mathrm{J}$ Am Med Directors Assoc 2015 Oct;16(10):860-866. [doi: 10.1016/j.jamda.2015.04.012]

44. Degenholtz HB, Resnick A, Lin M, Handler S. Development of an applied framework for understanding health information technology in nursing homes. Journal of the American Medical Directors Association 2016 May;17(5):434-440. [doi: 10.1016/j.jamda.2016.02.002]

45. Market Research Report. Fortune Business Insights. 2020. URL: https://www.fortunebusinessinsights.com/ electronic-health-records-ehr-market-102660 [accessed 2021-02-16]

\author{
Abbreviations \\ EHR: electronic health record \\ ICC1: intraclass correlation coefficient 1 \\ IT: information technology \\ NH: nursing home \\ $\mathbf{R N}$ : registered nurse \\ SHURP: Swiss Nursing Home Human Resources Project
}

Edited by G Eysenbach; submitted 06.08.20; peer-reviewed by SB Ho, R Chan, Z Reis; comments to author 21.12.20; revised version
received 30.12.20; accepted 17.01.21; published 02.03.21
Please cite as:
Ausserhofer D, Favez L, Simon M, Zúniga F
Electronic Health Record Use in Swiss Nursing Homes and Its Association With Implicit Rationing of Nursing Care Documentation:
Multicenter Cross-sectional Survey Study
JMIR Med Inform 2021;9(3):e22974
URL: $\underline{\text { https://medinform.jmir.org/2021/3/e22974 }}$
doi: $\underline{10.2196 / 22974}$
PMID: $\underline{3650983}$

CDietmar Ausserhofer, Lauriane Favez, Michael Simon, Franziska Zúñiga. Originally published in JMIR Medical Informatics (http://medinform.jmir.org), 02.03.2021. This is an open-access article distributed under the terms of the Creative Commons Attribution License (https://creativecommons.org/licenses/by/4.0/), which permits unrestricted use, distribution, and reproduction 
in any medium, provided the original work, first published in JMIR Medical Informatics, is properly cited. The complete bibliographic information, a link to the original publication on http://medinform.jmir.org/, as well as this copyright and license information must be included. 